Check for updates

Cite this: J. Mater. Chem. C, 2021 , 9, 12972

DOI: 10.1039/d1tc90191e

rsc.li/materials-c

\section{Journal of Materials Chemistry C Editor's choice web collection: 'Spiro compounds for electronics'}

\author{
Cyril Poriel \\ Cyril Poriel introduces the Journal of Materials Chemistry C Editor's choice web collection on advances \\ in 'Spiro compounds for electronics'.
}

\section{Introduction}

Spiro configured compounds constitute one of the most important classes of organic semiconductors used in all of the devices of the emerging technologies of organic electronics. The origin of the success story of spiro compounds is linked to their particular geometry and the consequences on the structural, physical and electronic properties. Spiro compounds are constituted by the association of two molecular fragments linked by a shared tetrahedral carbon. Thus, spiro compounds possess a

Univ Rennes, CNRS, ISCR - UMR 6226, F-35000 Rennes, France.E-mail: Cyril.poriel@univ-rennes1.fr

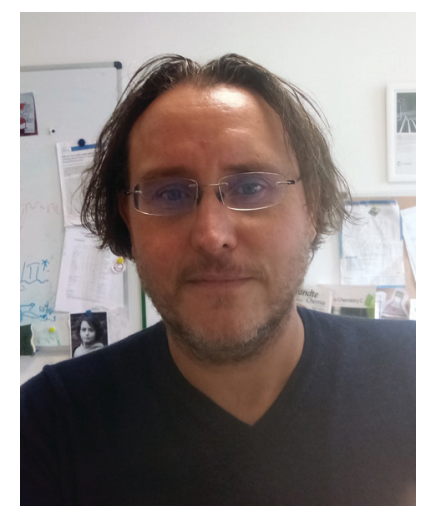

Cyril Poriel particular 3D geometry with the two fragments set along two orthogonal planes. This geometry is particularly appealing as the two branches of the molecule are only electronically slightly connecting (spiroconjugation), allowing the fine control of the electronic properties.

Since the display of the 'spiro concept' for organic electronics in the nineties by the Salbeck group, ${ }^{1} 9,9^{\prime}$-spirobifluorene (SBF), made by the association of two fluorene units via a shared spiro carbon, has become the flagship molecular structure of spiro compounds and is nowadays a central molecular scaffold in organic electronics. ${ }^{2-4}$

This fragment notably plays a key role in the field of solar cells, as the widely known hole transporting material 2,2' $, 7,7^{\prime}$-tetrakis[N,N-di(4-methoxyphenyl) amino]-9, $9^{\prime}$-spirobifluorene (Spiro-OMeTAD) is constructed on a SBF core. One of the particular properties of the SBF fragment (and of spiro compounds in general) is its capacity to improve the thermal and morphological properties of the organic semi-conductors in which it has been introduced. This is a key property for organic technologies.

For the last ten years, the spiro architecture has been particularly used to design host materials for phosphorescent OLEDs $^{5}$ and for thermally activated delayed fluorescence (TADF) OLEDs. ${ }^{6,7}$
Indeed, in these two technologies, the host material usually gathers an electron-rich and electron-poor fragment and these two fragments should be spatially separated. In this type of design, the spiro architecture appears to be ideal.

In the present collection, the great diversity of spiro compounds in the technologies of organic electronics is presented. I have selected outstanding papers published during recent years in Journal of Materials Chemistry $C$ and Materials Advances that highlight advances in spiro compounds for electronic applications. These articles provide exciting results that span a wide range of applications, including as host materials for phosphorescent OLEDs, fluorescent and TADF emitters for OLEDs, visual sensory materials, non-fullerene acceptors for solar cells, hole transporting materials etc.

\section{References}

1 T. P. I. Saragi, T. Spehr, A. Siebert, T. Fuhrmann-Lieker and J. Salbeck, Spiro Compounds for Organic Optoelectronics, Chem. Rev., 2007, 107, 1011.

2 C. Poriel, L. Sicard and J. Rault-Berthelot, New generations of spirobifluorene regioisomers for organic electronics: tuning electronic properties with the 
substitution pattern, Chem. Commun., 2019, 55, 14238.

3 C. Poriel and J. Rault-Berthelot, Structureproperty relationship of 4-substitutedspirobifluorenes as hosts for phosphorescent organic light emitting diodes: an overview, J. Mater. Chem. C, 2017, 5, 3869.

4 Q. Wang, F. Lucas, C. Quinton, Y.-K. Qu, J. Rault-Berthelot, O. Jeannin, S.-Y. Yang,

F.-C. Kong, S. Kumar, L.-S. Liao, C. Poriel and Z.-Q. Jiang, Evolution of pure hydrocarbon hosts: simpler structure, higher performance and universal application in RGB phosphorescent organic light-emitting diodes, Chem. Sci., 2020, 11, 4887.

5 C. Poriel and J. Rault-Berthelot, Designing Host Materials for the Emissive Layer of Single-Layer Phosphorescent Organic Light-Emitting Diodes: Toward Simplified Organic Devices, Adv. Funct. Mater., 2021, 31, 2010547.
6 M. Y. Wong and E. Zysman-Colman, Purely Organic Thermally Activated Delayed Fluorescence Materials for Organic Light-Emitting Diodes, $A d v$. Mater., 2017, 29, 1605444.

7 Z. Yang, Z. Mao, Z. Xie, Y. Zhang, S. Liu, J. Zhao, J. Xu, Z. Chi and M. P. Aldred, Recent advances in organic thermally activated delayed fluorescence materials, Chem. Soc. Rev., 2017, 46, 915. 